\title{
Analysis on the Old Gob Water Inrush Accident of Kunlun Mine in Zibo
}

\author{
Jiang Hua ${ }^{1}$, Gai Wenren ${ }^{1}$, Zhao Fu ${ }^{1}$, Zhang Xin ${ }^{2,3}$, Liu Hailin ${ }^{2,3}$ \\ (1.Administration of Coal Industry in Shandong Province, Jinan, Shandong 250031 \\ 2.College of Mining and Safety Engineering, Shandong University of Science and \\ Technology, Qingdao, Shandong 266590 3.National Key Laboratory of Mine \\ Disaster Prevention and Control (Cultivation Base), Qingdao 266590)
}

\begin{abstract}
This article was based on the serious water inrush accident of Kunlun Mine, Kunlun Town, Zichuan County, Zibo City. According to the old gob water inrush mechanism, combining with the results of the numerical simulation, it analyzes the causation and the conditions of this accident, discloses the evil consequence result in seeking economy benefit only and ignoring safety, and provides warning for future coal mining safety.
\end{abstract}

Keywords: old gob, water inrush, numerical simulation

\section{Introduction}

Since entering the new century, situation of coal mine production safety in China is on the turn, but can not see well: Before 2000, coal mining accidents in China killed tens of thousands of people each year; After 2000, the number began to be controlled under 7000; Death toll in 2003 was 6434; Expected number was under 5000 in 2004, but with the year-end two catastrophic accidents occurred, the number had been adjusted to 6000 . Chen Jiashan mine accident was identified as one of the biggest safety accidents in China's coal industry over 44 years.

At the end of 2003, Ministry of Finance, NDRC, State Bureau of Safe Production Supervision and Administration, China coal industry association had carried on the investigation and study to establish long-term effective mechanism of coal mine safety facilities according to the instructions of the state council. Through the investigation and analysis of 13 provinces, they drew a conclusion that coal mine safety debt amounted to more than 300 hundred million RMB, which determined the national coal mine safety debt was up to more than 500 hundred million RMB. People cared much more about the safety of coal production than any time before when the "people-oriented" statecraft was putt forward. Old gob water (ancient well, small kiln) disasters often cause local suspend production or flooded well and always lead to life injury. The old empty 
water disasters almost exist in all mines, its damage degree is associated with damage type. Old gob water inrush accident has no regularity, hard to predict, which can be accounted as the old gob water was produced in different time, place, and form with not identical outstanding performance characteristics.

The mechanics mechanism of old gob water inrush is both simple and complex, the simple side is that rock (column) has insufficient strength, the complex side is that there has been difficult that the critical value of water inrush depends on how thick wall (column), how big the rock strength and how to determine whether there exists old gob water around the production area is also very difficult. Currently there only has a general textual overview of prominent signs, it is difficult to express in precise mathematical form of knowledge, which is the objective factors of prevention and control of old gob water disasters.

The article based on the heavy old gob water inrush accident of Kunlun Mine ,Kunlun town, Zichuan county, Zibo city on April 2, 2004, analyzes the causation and the conditions of this accident, discloses the evil consequence result in seeking economy benefit only and ignoring safety, and provides warning for future coal mining safety.

\section{Analysis of Zibo city Kunlun coal mine gob water outburst accident}

\subsection{The overview of accident unit}

\subsubsection{The mine overview}

Kunlun mine was affiliated with Kunlun town collective enterprises. The mine is located in the east of Hui Cun. north of $\mathrm{Xi}$ Lishan village, east of Xiaofu river coast, Kunlun Town, Zichuan County, Zibo City.

Mine is a pair of inclined shaft, the main shaft wellhead elevation of +125.2 meters, the bottom elevation of -122.7 meters; auxiliary shaft wellhead elevation of +125.5 meters, the bottom elevation of -126.4 meters. Mining 1 or 2 coal seam.

Maximum mine inflow of water was $15 \mathrm{~m} 3 / \mathrm{h}$, the normal inflow of water was $10 \mathrm{~m} 3 / \mathrm{h}$, for two levels of underground drainage, the double drainage pipe, water storage capacity is $300 \mathrm{~m} 3$. The total mine drainage capacity is $54 \mathrm{~m} 3 / \mathrm{h}$.

The mine approved the construction in 1990 by the provincial administration of Coal Industry Bureau of Shandong coal [90] Document No. 380, 1993 completed and put into production, design capacity of 30000 tons / year, the approved capacity of 60000 tons / year. The mine on July 29, 2003 was listed as the Shandong provincial government suspends production for rectification of mine. On February 26, 2004 by Zibo Municipal People's Government assessment group acceptance and on March 15 by Shandong Province 
Government assessment group basic qualified acceptance, and put forward improvement requirements, mine after the rectification, the Zibo city government assessment group all qualified for the provincial government assessment group all questions the reinsertion, mine mass production started on March 27. Intermediate unauthorized opening 101 closed down the main roadway, construction of coal in three locations.

\subsubsection{The accident site overview}

On April 2, 2004, the mine production arranged three places for 103 downhill (province agreed to resume the assessment group all acceptance trial production bases), 2 layer coal south drift 202 uphill, 202 maser downhill. Water occurred in 202 south drift uphill advance head. The head began in April 2003, before the accident, the roadway has been heading 67.5 meters. This section of the roadway left has 2 residual mining heads, right has 1 residual mining head, water bursting point in 202 uphill head-on. As shown in Fig. 1.

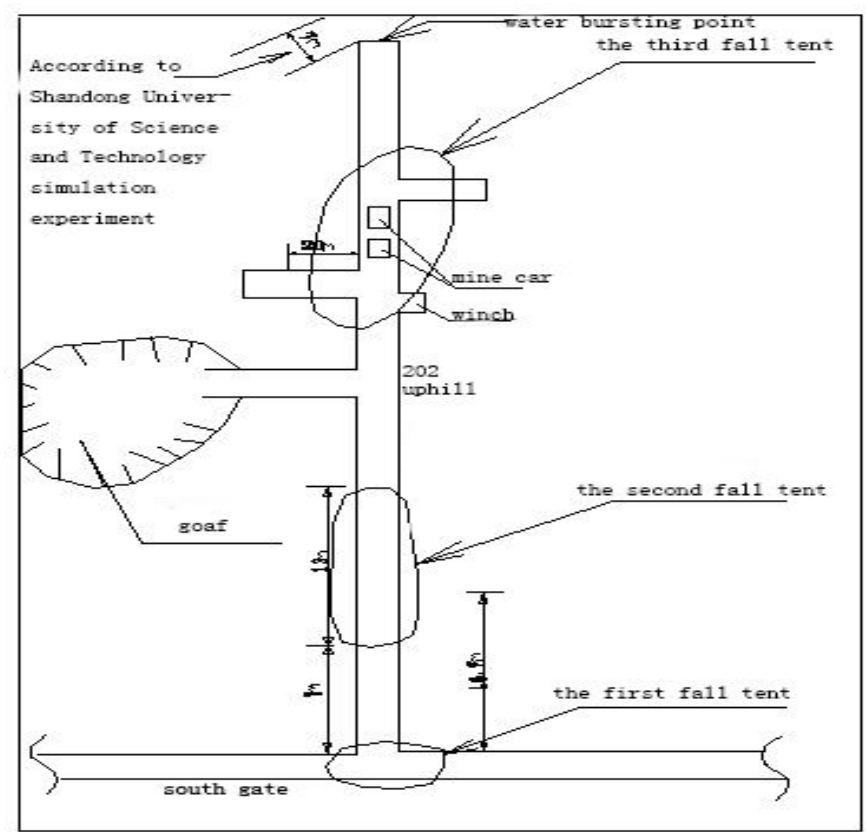

Fig. 1 Diagram of Kunlun coal mine gob water outburst accident

\subsection{Water inrush process}

Zibo city Kunlun Mine south drift 202 uphill working face had three job sites (202 uphill head, 202 uphill south crossheading, 202 uphill north crossheading), and arranged 6 people on duty in the job. April 2, 2004, miner Qu
Jiancheng went down at12:00, reached workplaces at 13:00, drilled at 14:00, and blasted last. The number of three operating drilling point was over 20, about 1.5 meters deep. Even found out floor wet at the positive head in the process of the coal mining, but it did not bring to enough attention. Completing the 
coal in uphill head and north crossheading at around 17:00, Qu Jiancheng was responsible for supporting and did not find abnormalities, when he supported uphill head first. At around 17:40, Qu Jiancheng reached the 202 uphill north head to support, hearing the "boom" about more than 10 minutes later, following a squalls wind and fog, and the head began water inrush.
There were 23 people trapped underground after the water inrush, and 19 people were rescued, four workers were killed finally at 3:30 on April 3. The accident caused a direct economic loss of 459,200 Yuan.

\subsection{Analysis of the accident}

\subsubsection{The direct cause of the accident}

The gob area of 2 layers, Kunlun Mine ,

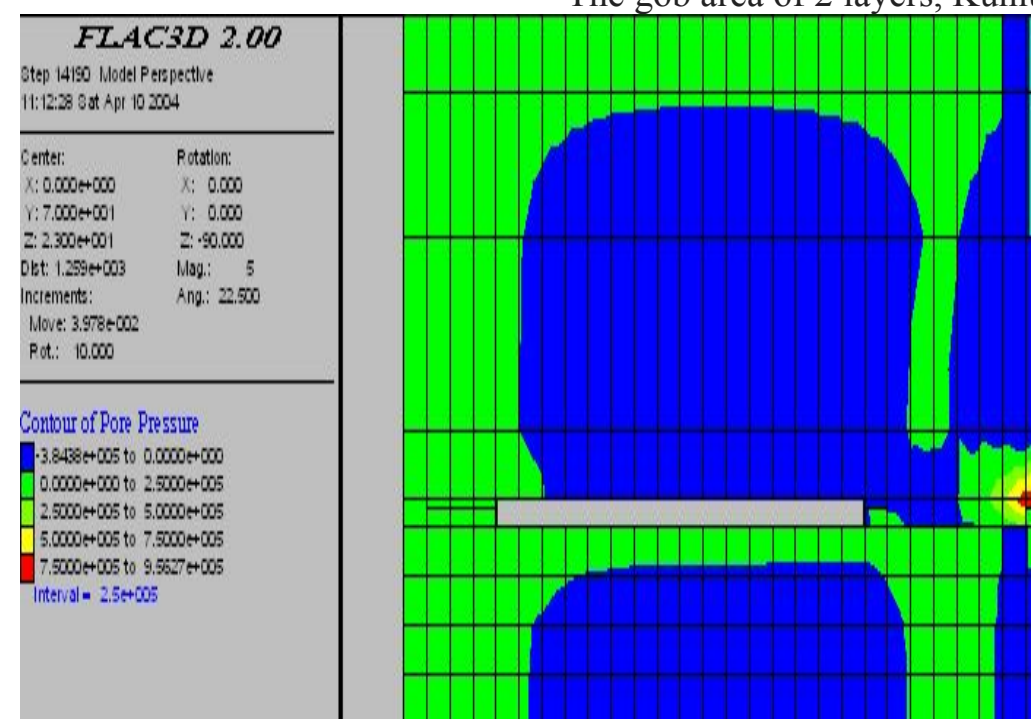

Fig. 2 The results of numerical simulation research
Zibo city had formed $-200.1 \mathrm{~m}-137.2 \mathrm{~m}$, a large area of water for a long time in 1996-1998, and did not make the region hydrological analysis, enforce strict probe drainage system, Open 101 main roadway of downhill without authorization, reach outside the place of acceptance location to mining operations. South drift 202 uphill head mined to the edge of water area, the thickness of the coal and rock pillars insufficient, strength not enough. The study of the numerical simulation of Shandong university of science and technology experts indicated that the distance between old gob water and coal wall only $7 \mathrm{~m}$ (Fig. 2 The results of the numerical simulation research), causing the water inrush because of the old gob water breaking through coal wall. Meanwhile, drawings painted not in time and accurate that was also one of the causes of the accident. The place of water inrush accident belonged to south drift 202 uphill coal roadway, interlinking with old gob water districts which located the south of 2 coal north drift 202 uphill, and the elevation of water inrush was $195.3 \mathrm{~m}$. From the analysis of data and field survey, 
the distance between a south roadway head marked on the original mining planar graph and 2 coal south drift 202 uphill head coal roadway was $60 \mathrm{~m}$, but the reality was that the place was half coal and rock roadway on original drawing. The mine mined forward in the original half coal and rock roadway head, but the length of mining in front of head, tilt up and down mining width, and others were not marked out on the drawings.

\subsubsection{The indirect cause of the accident}

1. The main person in charge of mining field lacked of safety consciousness who directed others open closed and entered the site to mining production without being accepted by the group of province and city. Did not analyze the water within the scope of the region, illegal commanded and did homework adventure, failed to carry out training for workers following stipulations. Escaping responsibility after the accident made it difficulties to the rescue work.

2. Mine managers forged closed, concealed the site of operation, avoided supervision of superior or the relevant departments, did not perform the drainage system, illegal commanded others open unsealing sealed unauthorized, and the safety of supervised and inspected was not in place.

3. Technical staff in charge of the mine did not analyze water within the scope of the region, follow the procedures and examine the feasible measures to drain.
4. Site management staffs have poor security awareness, lack of safety inspection, and not halt the behavior of no drain construction work.

5. posses the poor management, have no careful analysis of the investigation for the water damage inside mine field, lack of safety inspection, and supervision have serious dereliction of duty, and not stop unsealing the closed privately.

6. Fail to conscientiously implement requirements of province and city, have no analysis of the investigation for the mining water damage and drawings review relax supervision, lack of safety supervision.

7. The system of Coal administrative department of the regulation and safety responsibility did not $r$ implemented well

\section{Conclusions}

Under the background of safety investment debts many years and energy shortage, a lot of things should be done taking into account the efficiency of coal production and safety. Facing to the victims, only criticizing one-sided pursuit GDP and accusing of "disregard for life" was not enough. From the root and deep-seated structural reforms were the fundamental way for future work, but it was imperative to draw lessons from the accident occurred, and take active preventive measures, try to avoid major safety accidents.

1. The leading cadres at all levels and the relevant departments should draw lessons 
from this accident seriously. From the height of implementing the important thought of "Three Represents", held a highly responsible attitude for the party and the people, handled the relationship between safety and economic benefits correctly, established the "safety first" thinking firmly, strengthened the implementation of safe production responsibility system at various levels, took effective measures, stopped to illegal production behavior resolutely.

2. Pay attention to training, improve the quality of management of coal mine workers and staff's further, and hold certificates working.

3. Increase the intensity of accident hidden danger inspections. Especially for the mining water and the hidden trouble of "one ventilation and three prevention" should make regular analysis system, follow the project, capital, measures, time, Supervisor, supervisory principle of "six to implement", and pay attention to implementation.

4. Strengthen the management of mine technology, especially paint the drawings in time, reflect the real mining activities, and provide the basis for safety production.

5. Adhere to the "there is doubt that will explore, first probe after digging" principle, do the job of prevention and control water effectively, make the drain plans for the mining area, old gob, and area of water threaten, and set up special drain institutions to implement the capital, the responsibility.

\section{References:}

[1] National Coal Mine Safety Supervision Bureau developed, "Coal Mine Safety Regulations", 2001.

[2] Huang Shengxiang, "Introduction the prevention on the old gob water of zibo mine", Shandong Coal Science and Technology, 2012,(4).

[3] "The safety supervision and implementation detailed rulers of prevention coal mine water", Administration of Coal Mine Safety Supervision in Shandong Province, 2002 [4] "Regulations of prevention coal mine water", Coal industry press, Beijing. 2009.

[5] "Coal Mine Safety Regulations”, Coal industry press, 2011.

[6] "Present situation and measures of Shandong coal mine prevention water", Ren Zhongping, Shandong Coal Science and Technology, 2012.

[7] "Cause analysis of flooding accidents caused by goaf Water and Study on their counter measures", Guo Yanhua, China Safety Science Journal, 2006. 